\title{
La edición génica llama a las puertas del arte
}

\author{
Miguel Ángel Medina \\ Universidad de Málaga \\ medina@uma.es
}

\section{Introducción}

Arte y Ciencia han sido considerados como los «dos motores gemelos de la creatividad en cualquier cultura dinámica» (Wilson, 2010). De hecho, el científico y pensador Jorge Wagensberg identifica ciencia y arte con dos formas complementarias del conocimiento (Wagensberg, 1998). En el prefacio a la primera edición de Art \& Science de Eliane Strosberg reproducido en la segunda edición de 2015, el entonces director general de la UNESCO Federico Mayor Zaragoza señalaba que lo que es común al arte y la ciencia es el acto de creación que llevan asociado o -más precisamente-aquello que impulsa la creatividad humana (Mayor, 1999/2015). Mucho se ha escrito (incluyendo algunas contribuciones del autor de este ensayo) sobre la creatividad en los ámbitos de las artes y las ciencias y sobre sus parecidos y diferencias (Medina, 2006a; Medina, 2006b; Fierro y Heredia, 2013).

Suele citarse el evento 9 Evenings: Theater and Engineering, inaugurado en Nueva York el 13 de octubre de 1966 como «la primera colaboración a gran escala entre artistas, ingenieros y científicos» (Miller, 2014). A lo largo del siglo XX y en lo que llevamos del siglo XXI las interacciones entre ciencia y arte se han ido estrechando hasta el punto en que la ciencia de vanguardia o frontera está redefiniendo la práctica artística contemporánea, como apunta el subtítulo de Colliding Worlds de Arthur I. Miller (2014). Si para Miller el Cubismo fue la más radical vanguardia de principios del siglo XX, el artsci-identificado como un movimiento contemporáneorepresenta en la actualidad una vanguardia artística aún más extrema porque «no solo está influenciado por el arte y la tecnología como lo estuvo el cubismo, sino que sus artistas usan los medios científicos y tecnológicos, mientras que los cubistas usaron solo sus interpretaciones de las nuevas ideas» (Miller, 2014: 341). Como remarca el fundador y director del ZKM, Peter Weibel «el arte de hoy día es un producto de la ciencia y la tecnología» (citado en Miller, 2014: 107).
Como científico e historiador del arte, me interesan particularmente las influencias y mestizajes entre artes y ciencias. En otros momentos y lugares he escrito reflexiones sobre la obra artística -con una profunda base tecnológicade Cory Arcángel (Medina, 2011), sobre la teoría científica de redes y su aplicación en el arte (Medina, 2014) y sobre la influencia del Big Data en la práctica artística contemporánea (Medina, 2015). En el presente estudio, pretendo reflexionar sobre el Bio-Art (aquí denominado a partir de ahora bioarte) como una de las áreas donde en la actualidad se hace una práctica más radical del artsci y, por extensión, del arte y sobre la enorme influencia que en ello tiene la revolución científico-tecnológica del DNA recombinante.

\section{¿Qué es el bioarte? Algunos textos fundamentales}

En la historiografía del arte en lengua española relacionada con el tema que nos ocupa, una referencia obligada es la monografía Bioarte. Arte y vida en la era de la biotecnología, de Daniel López del Rincón (2015), quien señala que:

\footnotetext{
El término «bioarte» es un neologismo aparecido a principios del siglo XXI para designar genéricamente a un conjunto de prácticas artísticas que relacionan arte, biología y, muy frecuentemente, tecnología. Esto ha hecho del «bioarte» un término que acoge un grupo muy heterogéneo de prácticas cuyos límites no son siempre claros (López del Rincón, 2015: 11).
}

En la «Introducción» de Signs of Life. Bioart and Beyond (Kac, ed., 2007), obra multi-autores editada por MIT Press, el bioartista Eduardo Kac ofrece una de las más citadas definiciones de bioarte:

El bioarte es una nueva dirección del arte contemporáneo que manipula los procesos de la vida. Invariablemente, el 
bioarte emplea uno o más de los siguientes enfoques: (1) el tratamiento de biomateriales en específicas formas inertes o comportamientos; (2) el uso subversivo o inusual de herramientas y procesos biotecnológicos; y (3) la invención o transformación de organismos vivos con o sin integración social o medioambiental (Kac, ed., 2007: 18).

Suele mencionarse como precursores del bioarte a tres genios de la ciencia, la fotografía y la pintura. Sir Alexander Flemming (1881-1955), descubridor de la penicilina por serendipia y premio Nobel en 1945, fue un científico interesado en el arte que creó en los años veinte lo que denominó germ paintings: cultivando bacterias cromogénicas (esto es, generadoras de pigmentos) sobre placas con gel nutritivo de agar generaba composiciones con un punto naif que podían secarse y montarse sobre papel. Prácticamente por los mismos años, el gran fotógrafo Edward Steichen (1879-1973) comenzó a interesarse en las posibilidades artísticas del cultivo de plantas y la obtención de variedades empleando tratamientos farmacológicos. El MoMA organizó una exposición en 1936 de las variedades de Delphinium con flor de Steichen, confiriéndoles un estatus de legitimación artística. El tercer precursor del bioarte fue Salvador Dalí (1904-1989), quien mantuvo un genuino interés por la ciencia toda su vida y se inspiró en descubrimientos candentes de la biología molecular como la estructura del DNA para realizar muchas de sus obras artísticas, como El Gran Masturbador en paisaje surrealista con ADN (1957-1958), Hommage à Crick et Watson (1963), Galacidalacidesoxyribonucleicacid (1963), Arabes désoxyribunocléiques (1963), El ácido desoxirribonucleico y la escalera de Jacob (Homenaje a Severo Ochoa) (1975), La estructura del ADN (1975-1976), El pie de Gala (1975-6) y El camino del enigma (1981).

La obra más influyente de la bioartista Suzanne Anker es su extensa producción escrita. La repercusión que tuvo Gene Culture: Molecular Metaphor in Visual Art (Anker, 1994/2000) condujo a la publicación de un especial de la revista Art Journal titulado «Contemporary Art and the Genetic Code. New Models and Methods of Representation» (Levy y Sichel, eds., 1996), que incluía un texto suyo (Anker, 1996). En colaboración con la socióloga Dorothy Nelkin (1933-2003), publicó un artículo sobre la influencia de la genética en el arte contemporáneo (Nelkin y Anker, 2002) y -sobre todo- el libro fundamental sobre la reflexión e historia de la tendencia biotemática del bioarte: The Molecular Gaze: Art in the Genetic Age (2004). A estas obras han seguido otros artículos firmados por Anker en solitario o en colaboración (Frazzetto y Anker, 2009; Anker, 2014a, 2014b, 2015a, 2015b).

George Gessert es autor de una limitada pero influyente bibliografía sobre «arte genético» (Gessert, 1993, 1999, 2010). El bioartista Joe Davis ha reflexionado sobre el «arte genético» (Davis, 2007) y ha sido coautor de una revisión sobre bioarte en la revista científica Trends in Biotechnology (Yetisen et al., 2015). Bioart and the Vitality of Media (2010) de Robert Mitchell ha sido presentado como la primera reflexión teórica comprensiva de esta forma de arte para situarla en los contextos de la historia del arte, de la práctica del laboratorio y de la teoría de los medios. Es imprescindible mencionar la revista Leonardo editada por MIT Press, que en los últimos 20 años ha sido órgano de difusión de propuestas bioartísticas y ámbito de reflexión sobre diversas tendencias bioartísticas, como las recogidas en dos libros electrónicos que contienen selecciones de artículos de Leonardo relacionados con el bioarte: Art, Humanities, and Complex Netwoks (Schich et al., 2012) y Meta-Life. Biotechnologies, Synthetic Biology, ALife and the Arts (Bureaud et al., 2015).

La práctica del bioarte va acompañada de profundas reflexiones sobre temas centrales de la ética y la filosofía actuales: ¿Cuáles son las fronteras entre lo vivo y lo no vivo? ¿Hay espacio para lo «semi-vivo»? ¿Se debe y se puede limitar las capacidades de la humanidad de afectar a las propias condiciones de habitabilidad del planeta Tierra? ¿Hay fronteras bioéticas para la manipulación de genes, de tejidos, de órganos o incluso de organismos? ¿Qué posición tomar ante las posibilidades científico-tecnológicas que se nos abren de acelerar la evolución biológica y la de la misma especie humana? A modo de ejemplos, la práctica del bioarte ha estimulado la reflexión sobre el Antropoceno (Anker, 2014a, 2015a; Myers, 2015). También está empezando a generar reflexiones y debates sobre el transhumanismo (Pet, 2016), ese movimiento que, de acuerdo con el filósofo Antonio Diéguez (2017), preconiza el libre uso de la tecnología para el «mejoramiento» del ser humano, trascendiendo todos sus límites actuales, dando lugar a una o múltiples nuevas especies trans-humanas. 


\section{Varios bioartistas y piezas emblemáticas de bioarte}

El estadounidense George Gessert (1944) usa el cultivo y selección de plantas como medio de expresión artística, como ilustró Iris Project en el New Langton Arts de San Francisco (1985).

Mucho más radical en sus postulados y procedimientos, el estadounidense Joe Davis (1950) fue el primer artista que utilizó la tecnología del DNA recombinante como herramienta para la creación de «obras artísticas basadas en el DNA». Su «Microvenus» (1986) fue la primera «molécula de DNA artística» de la historia del bioarte.

La estadounidense Suzanne Anker (1946) ha centrado parte de su obra artística en representaciones/reproducciones de cromosomas, las unidades discretas en que se empaqueta el genoma de los seres vivos ${ }^{1}$, como en Zoosemiotics [Primates, Frog, Gazelle, Fish] (1993). Su instalación Astroculture (Eternal Return) [1] formó parte de la exposición The Value of Food (catedral de San Juan el Divino, New York, octubre de 2015).

Tal vez no haya pieza más emblemática e icónica del bioarte biomedial que GFP Bunny (2000), del bioartista brasileño Eduardo Kac (1962). Se trata de un auténtico conejo albino producto de la tecnología del DNA recombinante al que denominó Alba. El caso de Alba no era ninguna novedad en el campo de la investigación biológica. Lo que la hace única es el gesto de apropiación del artista y su voluntad de elevarlo al estatus de "obra de arte» con el título GFP Bunny. Las reminiscencias con los ready-made de Duschamp son evidentes. Otro de los proyectos fundamentales de Kac es Natural History of the enigma (2003-2007), comentada y explicada críticamente en la tesis de máster When CRISPR meets Art de Lotte Pet (2016), quien conecta dicho proyecto artístico con el movimiento trans-humanista.

En el último decenio está creciendo un movimiento de «empoderamiento» de la tecnología científica por la sociedad civil denominado DIY (del inglés Do It Yourself, «hazlo tú mismo»). El movimiento D/Y es particularmente activo en los campos de la biotecnología, tecnología del DNA recombinante, biomedicina regenerativa y biología sintética (Rodríguez-Caso, 2015). Kac se unió al movimiento D/Y, desplazando su producción hacia la tendencia más «bioactivista» del bioarte, en la que «militan» bioartistas como Beatriz da Costa, Natalie Jermijenko, Brandon Ballengée o

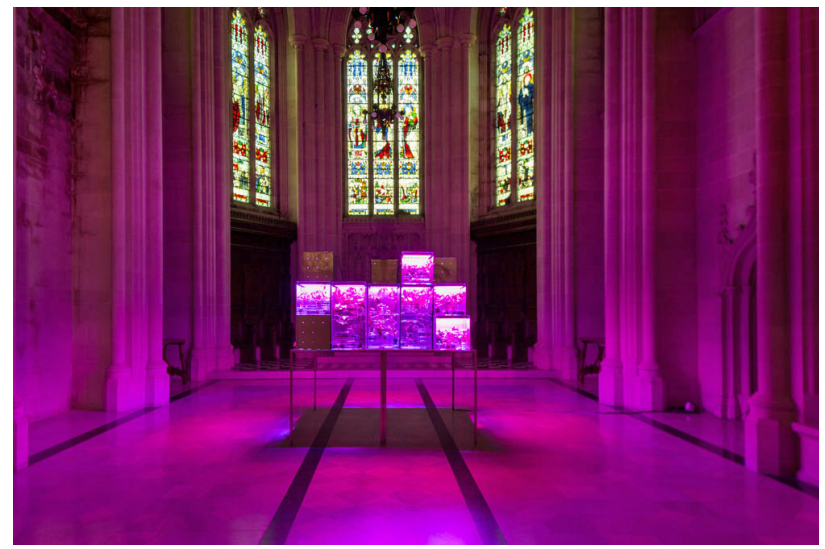

1. Astroculture (Eterna Return), de Suzanne Anker (2015). La instalación consistió en cubetas de plástico y acero galvanizado con suelo, agua y plantas crecidas a partir de sus semillas usando luces LED rojas y azules y evitando el uso de pesticidas. Fotografía de la propia autora con licencia Creative Commons 4.0

el colectivo Critical Art Ensemble. Así, en su obra Cypher (2009) Kac incluía un kit D/Y transgénico para que cualquiera tuviese la posibilidad de insuflar vida a su propia pieza de arte biológico.

Marion Laval-Jeantet y Benoît Mangin (conocidos como colectivo Art Orienté Object) propusieron una radical transición interespecífica en su proyecto May the Horse Live in Me (2001). Durante meses, Marion se sometió a tratamiento con inmunoglobulinas de caballo para evitar un posterior rechazo inmunitario. Este periodo de preparación incluía una comunicación ritual con un caballo en el que ella caminaba en su compañía usando unas pezuñas protésicas. Durante la etapa clave de la performance, Marion recibió transfusiones de sangre de caballo para posteriormente someterse a una extracción de su sangre «híbrida», que fue inmediatamente liofilizada y almacenada en sendos contenedores de aluminio grabados.

Los bioactivistas Critical Art Ensemble (colectivo fundado en 1987) colaboraron con los bioartistas Paul Vanouse y Faith Wilding para desarrollar el proyecto artístico Cult of the New Eve (1999-2000), performance en la que mimetizaron el lenguaje de un movimiento religioso, proponiendo un culto a las promesas de futuro de la biotecnología como una nueva forma de salvación. Los significados e implicaciones de este «nuevo culto» y el «advenimiento de un futuro transhumanista» han sido comentados por Pet (2016). 
En línea con el transhumanismo, el artista australiano de origen chipriota Stelarc (1946) tiene una dilatada trayectoria artística centrada en el concepto de «cuerpo extendido», bajo la premisa de que «el cuerpo está obsoleto». En «obras» como The Third Hand (1976-1984), Exoskeleton (1998) o Extended Arm (2000) exploró las posibilidades de la ortopedia biónica para superar las limitaciones de lo biológico. Más adelante exploró las posibilidades de la ingeniería tisular. Solicitó la colaboración del colectivo Tissue Culture \& Art para el diseño y elaboración de una oreja a partir de cultivos celulares, dando lugar a la pieza Extra Ear - 1/4 Scales (2003). Su proyecto Ear on Arm (desde 2006) ilustra la aspiración de Stelarc de trascender su biología humana.

\section{Bases biológicas del bioarte transgénico}

Todos los seres vivos poseen una «información genética» contenida en su genoma. El genoma de cada especie de ser vivo es la totalidad del DNA presente en cada una de las células de cada individuo de dicha especie. El DNA es una enorme molécula que resulta de la polimerización de cuatro tipos de monómeros (nucleotidos), frecuentemente identificados por las letras A, C, G, T, iniciales del nombre de la componente base nitrogenada de dichos monómeros.

La información genética contenida en el genoma suele compararse con un «libro de instrucciones» para posibilitar el despliegue de todas las funciones vitales, aquellas que permiten a los seres vivos mantenerse vivos. Ese «despliegue» de la información contenida en el genoma implica básicamente (1) la capacidad de sintetizar copias del genoma completo de cada célula antes de que se divida en dos para que cada célula «hija» herede una copia completa del genoma de la célula «madre» (replicación), y (2) la capacidad de "descodificar» la información de fragmentos concretos del genoma (los genes) para sintetizar «máquinas moleculares» efectoras que realizan y/o regulan las funciones vitales. La «descodificación» se realiza en dos etapas: una primera, transcripción, en la que fragmentos discretos del genoma son copiados a polímeros monocatenarios de RNA; y una segunda etapa de traducción en la que la secuencia del RNA es «leída» por unas «máquinas moleculares» lectoras y descodificadoras denominadas ribosomas posibilitando la síntesis de las «máquinas moleculares» efectoras (proteínas).
Los procesos de replicación, transcripción y traducción garantizan el «flujo de la información genética» que posibilita que la vida se mantenga y se expanda. Los progresos de la biología molecular de los años cincuenta y sesenta permitieron conocer cómo se lleva a cabo este flujo de la información genética. Ello unido a progresos técnicos que posibilitaron a los científicos aislar los ácidos nucleicos (DNA o RNA) in vitro y "cortarlos» y "pegarlos" a la carta despejaron a partir de 1975 el camino para una de las más grandes revoluciones científico-tecnológicas contemporáneas: la asociada a la tecnología del DNA recombinante. Con ella, el ser humano había adquirido la capacidad de generar de forma consciente, premeditada y predeterminada moléculas de DNA recombinante nunca antes presentes en la naturaleza, combinando fragmentos de DNA (y, por tanto, «información genética») de organismos distintos. La adquisición de esta capacidad posibilitó generar organismos modificados genéticamente (OMG, o GMO en su acrónimo inglés) o transgénicos.

El bioarte transgénico hace uso de la tecnología del DNA recombinante para generar obras de bioarte ligadas a esta novedosa capacidad del ser humano de manipular la «información genética». $Y$ hace uso de este conocimiento bien acríticamente como unos meros procedimientos y técnicas que ayudan al fin de crear nuevas obras de bioarte, bien para poner en cuestión y analizar críticamente esta asombrosa nueva capacidad de la humanidad, con sus luces y sus sombras, sus potenciales y sus peligros.

\section{La edición génica en pocas palabras}

La edición génica permite modificar de forma dirigida el genoma de un ser vivo mediante la inserción, deleción, modificación o reemplazamiento preciso de secuencias de DNA predefinidas. Aunque se han descrito otros procedimientos de edición génica, en 2012 cuando se se describió la utilización del sistema CRISPR/Cas9 para una edición génica rápida, barata, sencilla y con una precisión sin precedentes (Jinek et al., 2012).

El acrónimo CRISPR alude a Clustered REgularly Interspaced Short Palindromic Repeats («repeticiones palindrómicas cortas agrupadas e interespaciadas regularmente») y fue propuesto por el biólogo español Francisco 
2. Esquema del sistema de inmunidad adquirida CRISPR/Cas de bacterias y arqueas en el que se basa el más preciso método descrito de edición génica, con enorme potencial de utilización en bioarte. Modificado de una Wikimage con licencia Creative Commons 4.0

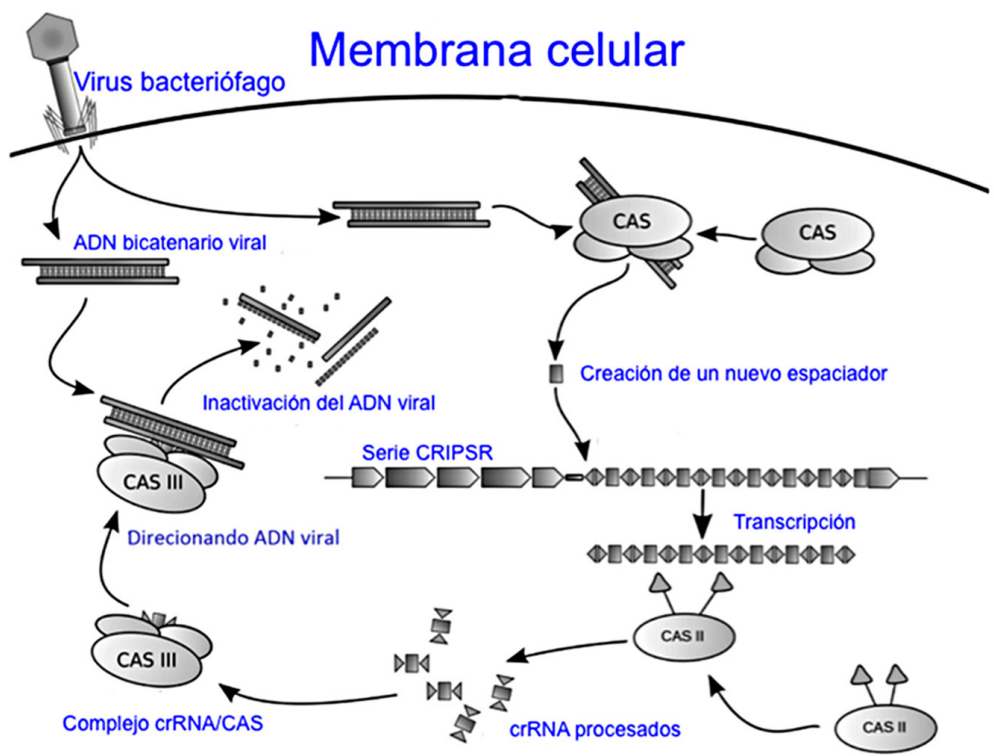

«memoria» en esos pequeños mensajes de "código Morse». Desde este momento la bacteria adquiere inmunidad frente a una posterior invasión por el mismo tipo de virus, ya que en estas circunstancias la secuencia palindrómica insertada en el genoma bacteriano podrá ser transcrita a RNA y dicho RNA podrá ser procesado por otras enzimas Cas (II) generando unos pequeños RNA que servirán de "guía» a una tercera familia de enzimas Cas (III) para interactuar con la región equivalente del DNA vírico y posibilitar que Cas lo corte, inactivándolo.

Lo que propusieron en 2012 los equipos de Doudna y Charpentier (Jinek et al., 2012) fue utilizar el tándem CRISPR/Cas como la más poderosa herramienta de edición génica descrita hasta la fecha, iniciando la más impactante revolución en la ingeniería biomolecular contemporánea, con un impacto sin precedente solo 3 años después en el campo de la investigación biomédica de 40 mil millones de dólares.

\section{¿Quién teme a CRISPR? El encuentro de CRISPR con el arte}

La tecnología CRISPR/Cas está facilitando que los seres humanos incrementemos enormemente la capacidad de con- 


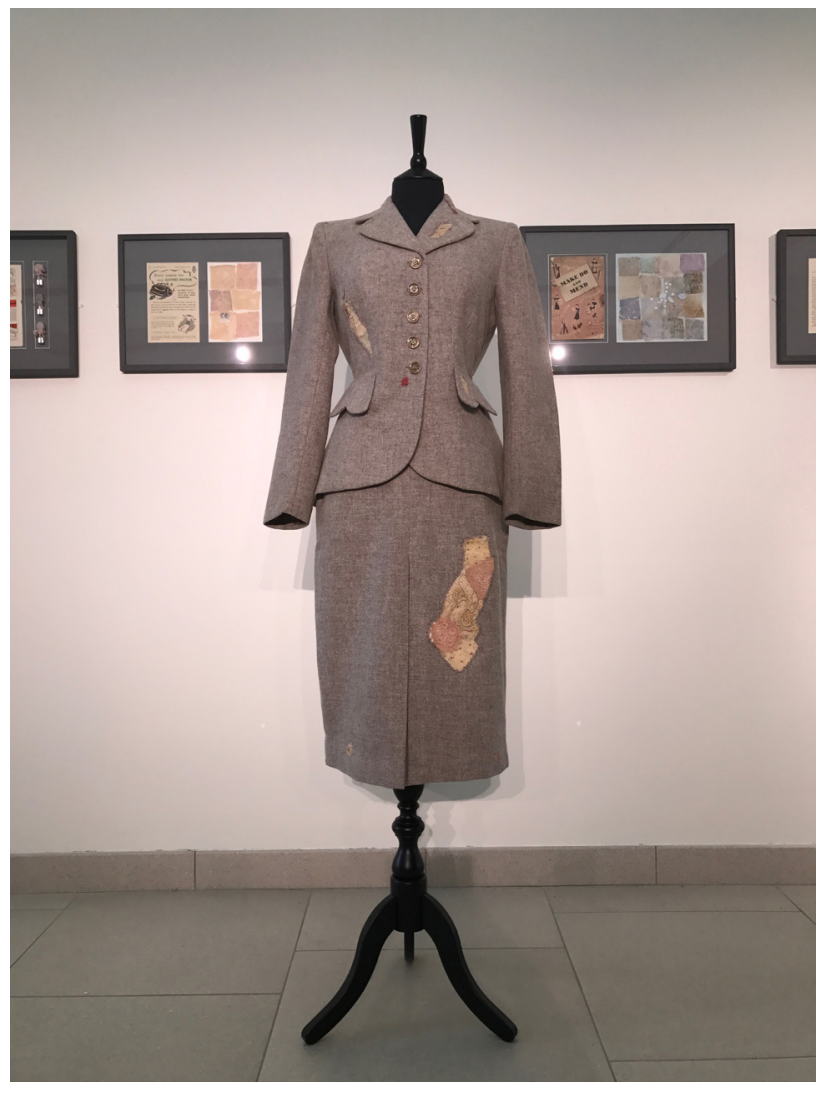

3. Make Do and Mend, de Anna Dumitriu (2017). Detalle de parte de la instalación expuesta por primera vez en LifeSpace Gallery (Dundee). Fotografía cortesía de la autora

trolar y modificar nuestro propio genoma. Y lo está haciendo de forma que esta capacidad empieza a estar en manos no solo de científicos especializados sino, potencialmente, de todo el mundo. Una reciente campaña de crowdfunding ha permitido que el Dr. Josiah Zayner ponga en marcha un proyecto de "democratización de la ciencia» consistente en ofrecer por 130 dólares un kit «Do It Yourself» que incluye todo lo necesario para editar con precisión genomas bacterianos en casa mediante la tecnología CRISPR/Cas (Kirksey, 2016). Posibilidades reales y tangibles como esta reavivan el debate acerca del transhumanismo, al que se hizo alusión más arriba.
Todo lo anterior lleva a plantear dos escenarios para el encuentro de CRISPR con el arte. Por una parte, dado que la práctica bioartística está empezando a generar reflexiones y debates acerca del transhumanismo, cabe esperar que esas reflexiones y debates empiecen a a incluir necesariamente reflexiones sobre las implicaciones de la edición génica y su «democratización». En esta línea, Eben Kirksey publicó en 2016 Who is Afraid of CRISPR Art? (Kirksey, 2016) en Somatosphere, un espacio web colaborativo que cubre las intersecciones de los estudios de ciencia, tecnología y sociedad, antropología médica, psiquiatría cultural, psicología y bioética. Por otra parte, esta tecnología ya está al alcance de los bioartistas y es prácticamente seguro que bioartistas individuales o colectivos y centros de estudio y praxis del bioarte de todo el mundo estén ya practicando la ejecución de «obras de bioarte» con el apoyo de la edición génica basada en la tecnología CRISPR. De hecho, en 2017 se exponía por primera vez una pieza de bioarte basada en el uso de la tecnología CRISPR. Su autora, la bioartista británica Anna Dumitriu concibió, desarrolló y presentó en la exposición Future Emerging Art and Technology (LifeSpace Gallery for Science and Art Research, Dundee, Escocia) la instalación Make Do and Mend (2017), que incluye un vestido de la Segunda Guerra Mundial con agujeros y remiendos a base de fragmentos de tela de seda teñida en la cual había crecido una cepa de la bacteria Escherichia coli modificada por edición génica basada en CRISPR [3]. Mas detalles sobre esta pieza de bioarte y su significado pueden encontrarse en una reciente breve nota sobre el tema publicada en la nueva revista científica The CRISPR Journal (Medina, 2018).

En el campo de la modificación génica, la pregunta es cada vez menos «¿qué se puede y qué no se puede hacer?» y va siendo desplazada por estas otras: «¿Qué se debe y qué no se debe hacer? ¿Se puede regular su uso? ¿Qué riesgos conlleva y cómo pueden evaluarse?...». La tecnología CRISPR ha venido para quedarse. Y, sin duda, impactará en la práctica, la reflexión y el estudio del bioarte en el más inmediato futuro. 


\section{Nota}

1 Por ejemplo, las células somáticas del ser humano contienen 23 pares de cromosomas, mientras que las células germinales humanas contienen una copia única de cada uno de los 23 tipos de cromosomas.

\section{Bibliografía}

ANKER, Suzanne (1994/2000), «Gene culture: molecular metaphor in visual art», Leonardo, n. ${ }^{\circ} 33$ (5), pp. 371-375. [Leonardo reproducía en 2000 un texto originalmente publicado en 1994 en Plaza Gallery, Fordham College, New York].

- (1996), «Cellular archaelogy», Art Journal, n. 55 (1), p. 33.

- (2014a), «The beginnings and the ends of Bio Art», Artlink, n. 34 (3). En: <http://www.suzanneanker.com/wp-content/uploads/2014-

The-beginnings-and-the-ends-of-Bio-Art-Bio-Art-Life-in-the-Anthropocene-Artlink-Magazine.pdf> (fecha de consulta: 14-09-2016).

- (2014b), «Prime objects and body doubles», Art Journal, n. 68 (4), pp. 99-104.

- (2015a), «Naturally hypernatural: visions of nature», Antennae, n. 33 , pp. 6-18.

- (2015b), «Petri(e)'s panoply», Antennae, n. ${ }^{\circ} 34$, pp. 5-16.

ANKER, Suzanne y NELKIN, Dorothy (2004), The Molecular Gaze: Art in the Genetic Age, Cold Spring Harbor Laboratory Press, Cold Spring Harbor.

BUREAUD, Annick, MALINA, Roger F. y WHITELEY, Louise (eds.) (2015), Meta-Life. Biotechnologies, Synthetic Biology, ALife and the Arts, Leonardo Ebook Series, MIT Press, Cambridge, Mass.

DAVIS, Joe (2007), «Cases for genetic art», en KAC, Eduardo (ed.), Signs of Life, MIT Press, Cambridge, Mass., pp. $249-266$.

DIÉGUEZ, Antonio (2017), Transhumanismo, Herder, Madrid.

FIERRO, Alfredo y HEREDIA, Antonio (2013), Cartas a una joven promesa, SPICUM, Málaga.

FRAZZETTO, Giovanni y ANKER, Suzanne (2009), «Neuroculture», Nature Reviews Neuroscience, n. 10 (11), pp. 815-821.

GESSERT, George (1993), «Notes on genetic art», Leonardo, n. 26 (3), pp. 205-211.

- (1999), «A history of art involving DNA», en STOCKER, Gerfried y SCHOPF, Christine (eds.), Ars Electronica 99 - Life Science, Springer, Vienna, p. 234.

- (2010), Green Light. Toward an Art of Evolution, MIT Press, Cambridge, Mass.

JANSEN, R., EMBDEN, J. D. A. V., GAASTRA, W. y SCHOULS, L. M. (2002), «Identification of genes that are associated with DNA repeats in prokaryotes. Moleculara Microbiology, n. ${ }^{\circ} 43$, pp. 1565-1575.

JINEK, M., CHYLINSKI, K., FONTANA, I., HAUER, M., DOUDNA, J. y CHARPENTIER, E. (2012), «A programmable dual-RNA guided DNA endonuclease in adaptive bacterial immunity", Science, n. ${ }^{\circ}$ 337, pp. 816-821.

KAC, Eduardo (ed.) (2007), Signs of Life, MIT Press, Cambridge, Mass.

KIRKSEY, Eben (2016), «Who is afraid of CRISPR art?». En: <http://somatosphere.net/2016/03/who-is-afraid-of-crispr-art.html> (Fecha de consulta: 16-11-2016).

LANDER, Eric S., (2016), «The heroes of CRISPR», Cell, n. ${ }^{\circ} 164$, pp. 18-28.

LEVY, Ellen K. y SICHEL, Berta M. (eds.) (1996), «Contemporary art and the genetic code. New models and methods of representation», Art Journal, n. ${ }^{\circ} 55$ (1)

LÓPEZ DEL RINCÓN, Daniel (2015), Bioarte. Arte y vida en la era de la biotecnología, Akal, Madrid.

MAYOR, Federico (1999/2015), «Foreword», en STROSBERG, E., Art \& Science (2nd, ed.), Abbeville Press, New York, pp. 7-8.

MEDINA, Miguel Ángel (2006a), «Creatividad en la ciencia, creatividad de la ciencia», Paradigma, n. ${ }^{\circ}$ 5, pp. 16-19.

- (2006b), «The pursuit of creativity», BioEssays, n. ${ }^{2}$, pp. 1151-1152.

- (2011), «Cory Arcangel juega con la vacuidad tecnológica», RevistArt, n. 156, pp. 16-17.

- (2014), «Network theory and its application in arts practice and history of arts», Rupkatha Journal, n. ${ }^{\circ} \mathrm{VI}(3)$, pp. 16-26.

- (2015), «Big Data and the arts», Rupkatha Journal, n. ${ }^{\circ}$ VII (1), pp. 12-20. 
MEDINA, Miguel Ángel (2018), "CRISPR gene editing meets the art world», The CRISPR Journal, n. ${ }^{\circ}$, pp. 317-318.

MILLER, Arthur I. (2014), Colliding Worlds, W.W. Norton \& Co., New York.

MITCHELL, Robert (2010), Bioart and the Vitality of Media, University of Washington Press, Seattle.

MOJICA, F. J. M., DÍEZ-VILASEÑOR, C., GARCÍA-MARTÍNEZ, J. y SORIA, E. (2005), «Intervening sequences of regularly spaced prokaryotic repeats derive from foreign genetic elements", Journal of Molecular Evolution, n. ${ }^{\circ}$ 60, pp. 174-182.

NELKIN, Dorothy y ANKER, Suzanne (2002), «The influence of genetics on contemporary art», Nature Reviews Genetics, n. 3 (12), pp. 967971.

PET, Lotte (2016), When CRISPR Meets Art, Master Thesis Arts and Culture, Leiden University, Leiden.

RODRÍGUEZ CASO, Carlos (2015), «La Biología Sintética y la comunidad DIY», Encuentros en la Biología, n. 0 153, pp. 7-10.

SCHICH, Maximilian, MEIRELLES, Isabel y MALINA, Roger (eds.) (2012), Arts, Humanities and Complex Networks, Leonardo Ebook Series, MIT Press, Cambridge, Mass.

WAGENSBERG, Jorge (1998), Ideas para la imaginación impura, Tusquets, Barcelona.

WILSON, Stephen (2010), Art + Science Now, Thames \& Hudson, London.

YETISEN, A., DAVIS, J., COSKUN, A. F., CHURCH, G. M. y YUN, S. H. (2015), «Bioart», Trends in Biotechnology, n. 33 (12), pp. $724-734$. 